\title{
Investigasi level miskonsepsi pada Hukum III Newton
}

\author{
Yudi Kurniawan \\ STKIP Singkawang \\ J1. STKIP, Kota Singkawang, Kalimantan Barat \\ Surat-e: yudikurniawanI012@gmail.com
}

Penelitian ini bertujuan untuk memberikan gambaran bentuk miskonsepsi dan seberapa tinggi miskonsepsi yang dimiliki oleh siswa kelas IX SMP Negeri di Pandeglang, Banten. Sampel yang dilibatkan dipilih secara purposive sampling dengan memilih responden yang telah mempelajari materi Hukum III Newton. Data penelitian yang diperoleh dianalisis secara deskriptif dan diolah untuk dikategorikan berdasarkan interval miskonsepsi. Instrumen yang dipakai dalam pengambilan data berupa tes diagnostik bertingkat tiga (three tier-tests) dan lembar konsepsi Hukum III Newton. Hasil penelitian menunjukkan bahwa seluruh responden mengalami miskonsepsi pada materi Hukum III Newton dengan rerata persentase $67.5 \%$ (kategori sedang). Data ini menunjukkan bahwa lebih dari separuh siswa pada sekolah sampel di Kab. Pandeglang mengalami miskonsepsi pada Hukum III Newton. Diharapkan data ini menjadi dasar untuk peneliti selanjutnya agar mengatasi miskonsepsi serta menggali miskonsepsi Hukum I Newton maupun Hukum II Newton.

This research aim is to give a clear description of misconception and the level of misconception on Newton Third Laws that was held by students (9th grade) in public junior high school in Pandeglang, Banten. The sample involved was chosen by purposive sampling from the student who has learned the Newton's Third Laws. Data was analyzed to be categorized based on the misconception interval descriptively. Instruments that used in this study was a three-tier data (three tier-tests) and the conception sheet. The results showed that all of the 9th-grade students (as the respondent in that school) were have the misconception of Newton's Third Laws (percentage of $67.5 \%$; medium category). It is suggested to the next researchers to overcome these misconceptions or finding the other form of misconceptions from Newton's 2nd Laws and Newton's Ist Laws.

Kata kunci: Miskonsepsi, level miskonsepsi, Hukum III Newton

\section{Pendahuluan}

Siswa berangkat menuju ke sekolah formal dengan membawa segala informasi di dalam kognitifnya sesuai apa yang dialaminya dalam kehidupan sehari-hari. Fakta ini dapat memberikan keuntungan sekaligus masalah bagi siswa. Siswa diuntungkan jika konsepsi awal yang dimilikinya telah sesuai dengan konsepsi ilmiah. Namun itu akan menjadi sebuah masalah kognitif yang baru bagi siswa yang memiliki perbedaan dengan konsepsi ilmiah yang diterimanya dalam kelas formal. Kesenjangan ini dapat memicu miskonsepsi [I][2].

... When students came to their class, they had kept their prior knowledge about their surrounding then they think about phenomenon during in the learning process. If their prior knowledge will useful to his new class, it was would give benefit to the students. However, if it different with scientific knowledge, it would be a trouble in the students' cognitive... [2].

Miskonsepsi memang bukan hal baru dalam pembelajaran termasuk pembelajaran fisika, akan tetapi masalah ini kerap muncul mengingat eratnya miskonsepsi dengan kejadian atau pengalaman sehari-hari yang keliru. cenderung membuat siswa resisten atas keyakinannya. Miskonsepsi merupakan kekeliruan dalam memaknai suatu konsep disebabkan adanya perbedaan antara konsepsi yang diyakini secara pribadi dengan konsepsi yang diyakini ilmuwan. Miskonsepsi yang dibiarkan begitu saja tanpa diberikan "pengobatan" dapat mengganggu proses penyerapan informasi pelajaran selanjutnya terutama pada konsep-konsep yang relevan [3]. 
Selain itu, siswa yang mengalami miskonsepsi diduga mengalami kesulitan untuk menguasai konsep. Penguasaan konsep erat kaitannya dengan metode mengajar yang bersifat informatif tanpa menggali pengetahuan siswa sehingga cenderung "membiarkan" konsepsi siswa apa adanya. Dengan demikian, penguasaan konsep bagi siswa yang terindikasi miskonsepsi juga tidak optimal [4].

Miskonsepsi yang banyak terjadi pada konsep fisika satu diantaranya ialah konsep Hukum III Newton. Hukum III Newton sebagai dasar dua Hukum Newton lainnya sehingga harus disampaikan dengan hati-hati sesuai dengan pengalaman yang mungkin dialami oleh peserta didik. Aplikasi pengetahuan yang cukup relevan dengan pemahaman Hukum III Newton dalam hal interaksi gaya (interaksi dua objek) misalnya terkait interaksi antar dua muatan listrik, interaksi benda yang berkaitan dengan kedudukannya (gravitasi), dan interaksi magnetik.

Dengan paradigma seperti itu, tentu sebuah keniscayaan bahwa seorang guru mengalami kesulitan dalam menentukan teknik mengajar yang tepat agar proses pembelajaran dan pembangunan konsep Hukum III Newton berjalan optimal. Selain itu, hambatan lainnya ialah guru juga mengalami kesulitan yang sama dengan muridnya dalam hal memaknai dan memahami redaksi Hukum III Newton yang berbunyi” untuk setiap (gaya) aksi ada (gaya) reaksi yang besarnya sama namun berlawanan arahnya". Dalam istilah sehari-hari diibaratkan sebagai "sebab dan akibat". Arti (gaya) reaksi dalam makna sehari-hari ialah gaya yang mengikuti adanya (gaya) aksi [5].

That is, the third law should be studied first, followed by the second and finally the first law as a natural sequence... The third law must be seen as underpinning the other two laws, and this means carefully scaffolding the ideas on a sound experiential basis....

This law is difficult for teachers and students in part because the traditional language is confusing. The expression "To every action there is an equal and opposite reaction" has entered everyday speech as a synonym for "cause and effect." "Reaction" in everyday speech is understood to follow action, not to be coincident [5].

Oleh karena itu, penelitian ini mencoba menggali segala kemungkinan miskonsepsi yang terkait Hukum III Newton sebagai dasar untuk menentukan langkah yang tepat untuk mengatasi miskonsepsi Hukum III Newton khususnya, dan Hukum Newton pada umumnya.

\section{Metode Penelitian}

\section{Subjek Penelitian}

Jumlah responden yang terlibat dalam penelitian ini berjumlah 64 orang pada satu diantara SMPN di Kabupaten Pandeglang, Provinsi Banten. Seluruh responden telah dipastikan telah mempelajari materi Hukum Newton untuk menghindari ambiguitas data apakah responden miskonsepsi atau justru tidak tahu konsep karena belum mempelajari materi yang diteliti.

\section{Instrumen dan Teknik Pengumpulan Data}

Instrumen yang digunakan dalam penelitian ini ialah tes bertingkat tiga (three tier-tests) yang dikhususkan membahas Hukum III Newton dan lembar konsepsi. Instrumen three-tier-test ini terdiri dari tier-I membahas pengetahuan konseptual tentang Hukum III Newton, tier2 membahas alasan memilih jawaban pada tier-I, dan tier3 memberikan tingkat keyakinan atas pilihan tier-I dan tier-2. Untuk analisis keputusan apakah responden tergolong orang yang memiliki miskonsepsi atau tidak, analisis jawaban siswa merujuk kepada [I].

Hasil penelitian yang diperoleh berupa data kualitatif tentang bentuk-bentuk (kalimat/ redaksi) miskonsepsi dan data kuantitatif tentang persentase jumlah siswa yang miskonsepsi. Dalam pengkategorian miskonsepsi, penelitian ini mengadopsi kategori miskonsepsi [6] seperti pada Tabel I berikut.

Tabel I. Kategori Miskonsepsi

\begin{tabular}{ccc}
\hline No & Rentang $(\%)$ & Kategori \\
\hline I & $0<$ miskonseps $i \leq 30$ & Rendah \\
2 & $30<$ miskonseps $i \leq 70$ & Sedang \\
3 & $70<$ miskonseps $i \leq 100$ & Tinggi \\
\hline
\end{tabular}

\section{Hasil Penelitian dan Pembahasan}

\section{Hasil Penelitian}

Dengan melakukan analisis data maka diperoleh hasil investigasi miskonsepsi Hukum III Newton (seperti Gambar I) dengan bentuk pernyataan miskonsepsi dirangkum bentuknya dan disajikan ringkasannya pada Tabel 2.

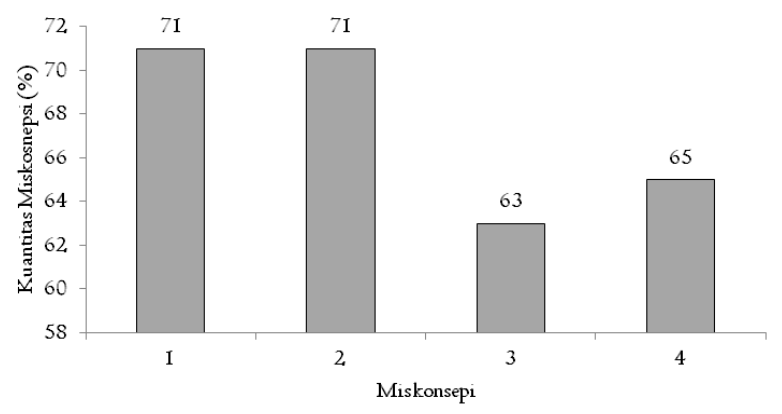

Gambar I. Distribusi Miskonsepsi Hukum III Newton

Keterangan:

$\mathrm{I}=$ miskonsepsi no.I

$2=$ miskonsepsi no.2, dst. 
Tabel 2. Bentuk Miskonsepsi Hukum III Newton

\begin{tabular}{cc}
\hline No & \multicolumn{1}{c}{ Pernyataan } \\
\hline I & Ketika dua benda bermassa sama $m_{1}=m_{2}$ tetapi \\
& $v_{1}=0$ dan $v_{2}=v$ saling berinteraksi (bertumbukan) \\
& maka gaya aksi reaksi yang dihasilkan oleh $m_{2}$ lebih besar \\
& dibandingkan $m_{1}$. \\
$2 \quad$ & Ketika dua benda dengan massa berbeda $m_{1}<m_{2}$, \\
& $v_{1}=0$ dan $v_{2}=v$ saling berinteraksi (bertumbukan) \\
& maka gaya aksi reaksi yang dihasilkan oleh $m_{2}$ lebih besar \\
& dibandingkan $m_{1}$. \\
Gaya aksi-reaksi terjadi pada satu benda & Ketika dua benda dengan massa berbeda $m_{1}<m_{2}$ tetapi \\
& $v_{1}=v_{2}$ saling berinteraksi (bertumbukan) maka gaya aksi \\
& reaksi yang dihasilkan oleh $m_{2}$ lebih besar dibandingkan \\
& $m_{1}$.
\end{tabular}

Berdasarkan hasil Gambar I, rata-rata persentase miskonsepsi yang dimiliki oleh responden sekitar 67,5\% (kategori sedang). Miskonsepsi yang paling kecil persentasenya terdapat pada Mis-3 dengan nilai 63\%. Hal ini merupakan fakta yang kurang baik karena miskonsepsi berada di atas kategori rendah (berada di atas 30\%) sehingga perlu dikaji lebih mendalam tentang bentuk miskonsepsi ini.

\section{Pembahasan}

Untuk memberikan gambaran miskonsepsi secara menyeluruh, maka berikut ini disajikan berturut-turut contoh soal dan jawaban siswa terhadap permasalahan Hukum III Newton, sedangkan Gambar 2 merupakan contoh jawaban siswa pada lembar konsepsi yang mengandung miskonsepsi (siswa yang teridentifikasi miskonsepsi).

\section{Contoh soal:}

\section{Miskonsepsi:}

Gaya aksi-reaksi terjadi pada satu benda

\section{Soal:}

Perhatikan gambar pada bagian akhir soal. Terdapat beberapa gaya yang bekerja pada sebuah balok yang diam di meja. Tentukanlah pasangan gaya yang merupakan pasangan gaya aksi-reaksi!
A. $w$ dengan $\mathrm{N}$
B. $w$ dengan $w^{\prime}$
C. $w^{\prime}$ dengan $\mathrm{N}^{\prime}$

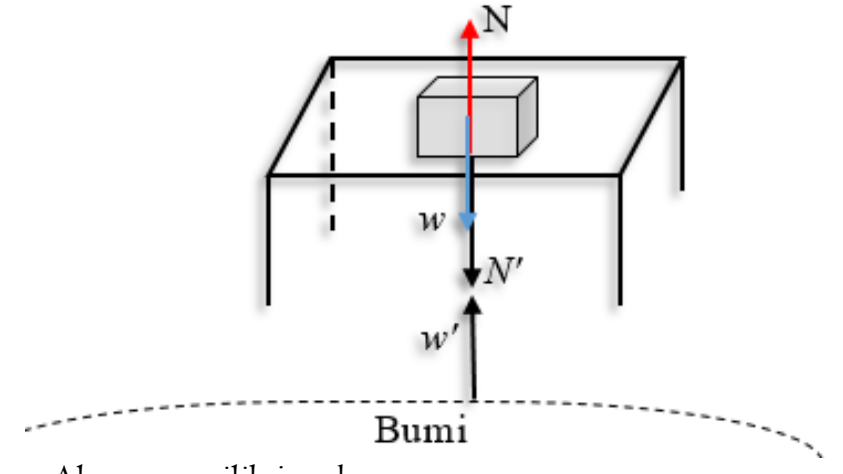

Alasan memilih jawaban:

\section{A. Karena gaya aksi-reaksi adalah gaya yang timbul karena adanya interaksi dua benda.}

B. Gaya aksi-reaksi adalah gaya yang timbul untuk mengimbangi gaya lain yang bekerja pada sebuah benda

C. Gaya aksi-reaksi adalah gaya yang timbul agar resultan gaya yang bekerja pada benda sama dengan nol

D. $\ldots$

Keyakinan pilihan:
A. Yakin
B. Tidak Yakin

Analisis siswa yang memiliki konsepsi ilmiah adalah yang memilih option A (tier-1), option A (tier-2) dan yakin atas jawabannya. Berat benda yang dipengaruhi oleh gravitasi berpasangan dengan gaya normal meja-benda. Dengan demikian, siswa yang memiliki konsepsi ilmiah akan sangat berhati-hati dalam memilih option pada gambar.

Selain menggunakan tes diagnostik bertingkat tiga (three tier-test), peneliti juga berusaha mempertajam data dengan memberikan lembar konsepsi yang diisi selama siswa memperhatikan demonstrasi yang disajikan oleh peneliti. Lembar konsepsi ini diisi secara individu dan dikumpulkan diakhir pembelajaran.

Adapun bentuk demonstrasi yang disajikan adalah sebagai berikut.

- Sebuah benda (penghapus) diletakkan di atas meja guru. Peneliti meminta siswa menentukan apakah ada gaya yang bekerja pada benda diam di atas meja tersebut. Pertanyaan-pertanyaan selanjutnya memiliki redaksi sesuai dengan Gambar 2.

Demonstrasi ini digunakan untuk mengungkap miskonsepsi No.3 yaitu "gaya aksi-reaksi terjadi pada suatu benda". Konsep yang benar ialah gaya aksi-reaksi terjadi pada dua benda. Oleh karena itu, miskonsepsi ini diungkap melalui selembaran pertanyaan yang salah satu pertanyaannya adalah untuk mendapatkan informasi keyakinan siswa dalam menjawab. Data ini tentu mendukung data hasil analisis three-tier test yang tersaji pada Gambar I. 
Pada Gambar 2, terdapat kesinambungan kekeliruan siswa dalam menjawab atau mengutip informasi yang telah ditampilkan melalui demonstrasi. Siswa secara konsisten menentukan bahwa terdapat pasangan gaya aksi-reaksi pada benda yang diam di atas meja. Kesalahan konsep terus digali hingga terungkap kekeliruan pada saat menggambar diagram bebas gaya pada benda tersebut. Bahkan, siswa tidak tepat menggambar diagram gaya pada meja yang digambar ke arah kiri. Keputusan miskonsepsi tergambar jelas saat siswa membubuhkan keyakinan pada akhir isiannya pada lembar konsepsi.

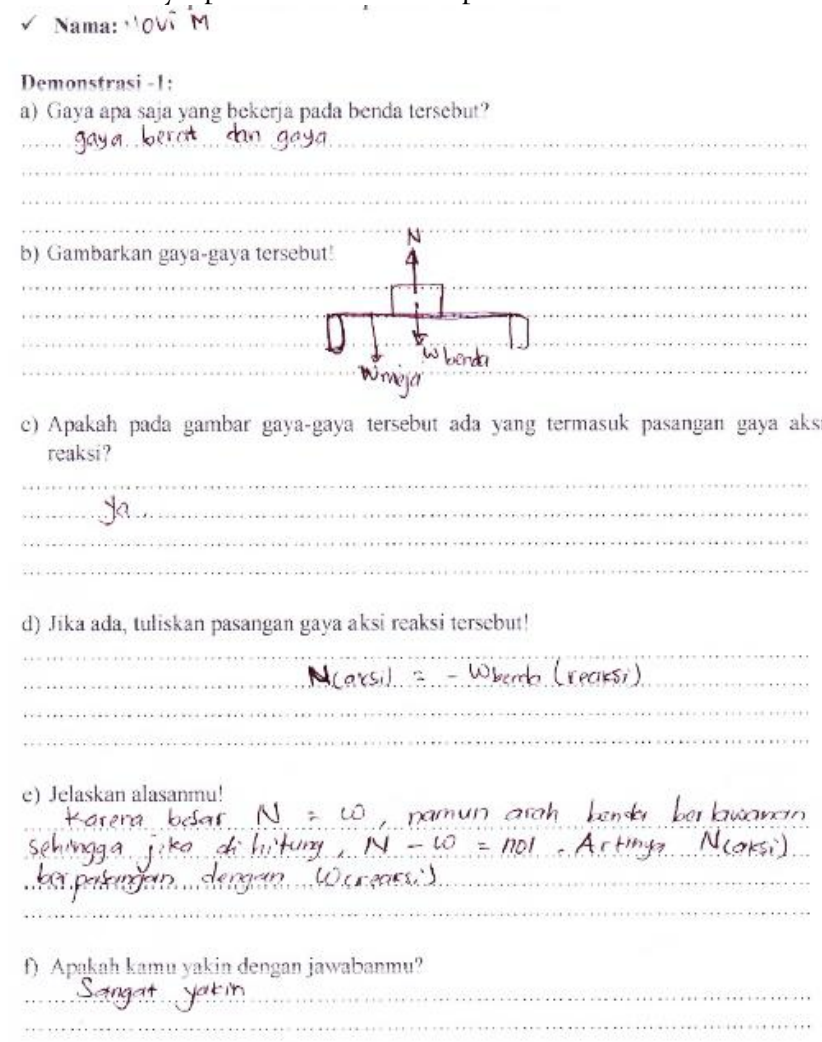

Gambar 2. Jawaban siswa yang miskonsepsi

Pada Gambar 2, miskonsepsi no 3 ini diyakini oleh siswa karena siswa keliru memahami resultan gaya dengan gaya, siswa juga keliru menganggap karena normal ke arah atas sedangkan berat menuju bawah (seharusnya menuju pusat bumi) sehingga jika benda diam berarti nilai gaya normal $=$ nilai berat sehingga totalnya adalah nol (benda diam).

Selain itu pula, tertulis bahwa siswa menentukan (melalui gambar) bahwa pasangan gaya aksi-reaksi terjadi pada satu benda dan mereka meyakini jawaban tersebut. Oleh karena itu, keputusan ini menunjukkan bahwa siswa tersebut memiliki miskonsepsi pada Hukum III Newton.

Berdasarkan temuan, dapat diketahui bahwa responden sangat meyakini bahwa faktor massa dan kecepatan mempengaruhi gaya aksi-reaksi yang terjadi dalam suatu kasus tumbukan. Dalam penelitian ini, telah disampaikan kepada responden bahwa kejadian tumbukan berada pada satu sumbu kerja (biasa dikenal sebagai momentum linear).

Sebagian besar responden menganggap bahwa semakin besar massa benda maka gaya aksi-reaksi yang ditimbulkan semakin besar. Hasil pemikiran inilah yang menjadi persentase terbesar yaitu 7I \% (Mis-I dan Mis2). Setelah dikaji lebih lanjut, peneliti mendapatkan infomasi bahwa analogi seperti ini terjadi karena pengalaman sehari-hari yang diamati oleh responden misalnya tabrakan antara truk dengan sepeda motor. Mereka melihat dampak akibat tumbukan keduanya ialah kerusakan yang lebih parah pada sepeda motor dibandingkan dengan kerusakan yang dialami oleh truk. Pada kasus lainnya, misalnya dua buah benda bermassa sama namun memiliki kecepatan yang berbeda contohnya mobil yang sedang melaju menabrak mobil lain yang identik dalam keadaan terparkir di pinggir jalan. Faktanya menunjukkan bahwa kerusakan mobil yang melaju cenderung lebih parah dibandingkan mobil yang diam. Asumsi inilah yang menjadi dasar mereka menyelesaikan permasalahan terkait Hukum III Newton.

Hukum III Newton tentang gaya aksi reaksi menitikberatkan pada "interaksi" atau "kontak" benda sesaat sebelum kedua benda mengalami dampak adanya perubahan momentum. Pernyataan ini didukung oleh pustaka [7] yang menyatakan bahwa pada saat kontak terjadi dalam waktu yang sangat singkat, maka besar gaya pasangan aksi-reaksi yang dihasilkan kedua benda haruslah sama tidak tergantung massa maupun kecepatan. The key concept of this scenario is that size, mass, and speed have no effect on the magnitude of the forces in a force pair [7].

Analogi-analogi responden terhadap fenomena seharihari (tentang tabrakan antara truk dengan sepeda motor dan fenomena sejenisnya) sudah mencakup aplikasi Hukum II Newton karena besar gaya sudah tidak sama, percepatan juga tidak sama sehingga terjadi perubahan antara kondisi awal dengan kondisi akhir. Seperti telah diketahui bahwa dampak penerapan gaya ialah adanya perubahan bentuk, perubahan posisi, dan perubahan kecepatan [8].

Dengan ditemukannya miskonsepsi ini, diharapkan pada penelitian selanjutnya berupaya untuk mengatasi agar permasalahan ini terselesaikan.

\section{Kesimpulan}

Dari hasil analisis dan pembahasan yang dilakukan, ditemukan bahwa terdapat miskonsepsi pada Hukum III Newton dengan rata-rata persentase $67 \%$ dengan kategori sedang. Secara spesifik temuan miskonsepsi disajikan pada pembahasan khususnya Tabel 2. Direkomendasikan kepada peneliti selanjutnya untuk menggali miskonsepsi pada materi Hukum Newton yang lain atau menemukan solusi penyelesaian masalah hukum Newton 


\section{Kepustakaan}

[I] R. Muliyani, I. Kaniawati, and L. Hasanah, "The Three-Tier Test (TTT) for Identify the Quantity of Student's Misconception on Archimedes's Laws," in Proceedings International Seminar on Mathematics, Science and Computer Science Education. Section: Physics and Physics Education, 2015, pp. 314-318.

[2] R. Muliyani and I. Kaniawati, "Identification of Quantity Students' Misconceptions on Hydrostatic Pressure with Three Tier-Test," in FULL PAPER PROCEEDING GTAR- 2015, 2015, vol. 2, pp. 7I6-720.

[3] P. R. Artiawati, R. Mulyani, and Y. Kurniawan, "Identifikasi Kuantitas Siswa Yang Miskonsepsi Menggunakan Three TierTest Pada Materi Gerak Lurus Beraturan (GLB)," JIPF (Jurnal Ilmu Pendidik. Fis., vol. I, no. I, pp. I3-15, 2016.

[4] R. Silviany, R. Muliyani, and Y. Kurniawan, "Penerapan Three Tier-Test Untuk Identifikasi Kuantitas Siswa yang Miskonsepsi Pada Materi Magnet," J. Ilmu Pendidik. Fis., vol. 2, no. I, pp. I0II, 2017.

[5] S. Stocklmayer, J. P. Rayner, and M. M. Gore, "Changing the Order of Newton's Laws-Why \& How the Third Law Should be First," Phys. Teach., vol. 50, no. 7, p. 406, 2012.

[6] Y. Kurniawan and A. Suhandi, "The Three Tier-Test for Identification The Quantity of Students' Misconception on Newton's First Laws," in FULL PAPER PROCEEDING GTAR-2015, 2015, vol. 2, pp. 313-319.

[7] J. Lutz, K. Sylvester, K. Oliver, and D. Herrington, "3, 2, I ... Discovering Newton's Laws,” Phys. Teach., vol. 55, no. I, pp. I49-I5I, 2017.

[8] Gsenviro, Explain how a force may produce a change in size or shape of an object? " eNotes, I0 Jan 2016, Website: https://www.enotes.com/homework.help/explain-that-forcemay-produce-change-size-shape-578065.

Diakses tanggal I6 Januari 2018. 